\title{
Association between maternal depression and child stunting in Northern Ghana: a cross-sectional study
}

\author{
Anthony Wemakor ${ }^{1 *}$ and Kofi Akohene Mensah²
}

\begin{abstract}
Background: Stunting indicates failure to attain genetic potential for height and is a well-documented indicator for poor growth. Depression is common in women of reproductive age and women's mental health problems may affect the growth of young children. We examined the association between maternal depression and stunting in mother-child pairs attending Child Welfare Clinic (CWC) in Northern Ghana.

Methods: An analytical cross-sectional study was performed involving mothers (15-45 years) and their children (0-59 months) who attended CWC at Bilpeila Health Centre, Tamale, Ghana. Socio-demographic data were collected using a semi-structured questionnaire, maternal depression was measured using Centre for Epidemiological Studies Depression Screening Scale, and anthropometry was conducted on children following standard procedures. The association between maternal depression and child stunting was examined in logistic regression adjusting for potential confounders.
\end{abstract}

Results: Prevalence rates of child stunting and maternal depression were estimated at 16.1 and $27.8 \%$ respectively in Northern Ghana. Mothers with depression when compared with those without depression tended to be younger, be currently unmarried, belong to the poorest household wealth tertile, and were more likely to have low birth weight babies, so these characteristics were adjusted for. In an adjusted multivariate logistic regression model, children of depressed mothers were almost three times more likely to be stunted compared to children of non-depressed mothers (Adjusted $\mathrm{OR}=2.48,95 \% \mathrm{Cl} 1.29-4.77, p=0.0011$ ).

Conclusions: There is a high prevalence of depression among mothers in Northern Ghana which is associated with child stunting. Further studies are needed to identify the determinants of maternal depression and to examine its association with child stunting to inform nutrition programming.

Keywords: Maternal depression, Stunting, Northern Ghana, Children, Mothers

Abbreviations: AOR, Adjusted odds ratio; CED-S, Centre for Epidemiologic Depression Screening; CWC, Child Welfare Clinic; SD, Standard deviation; WHO, World Health Organisation

\section{Background}

Stunting indicates a failure to achieve genetic potential for height and is a well-documented indicator for poor growth related to environmental and socio-economic circumstances [1]. Stunting is caused by long-term insufficient nutrient intake and/or frequent bouts of infections. The consequences of childhood stunting include

\footnotetext{
* Correspondence: anthonywemakor@yahoo.com

${ }^{1}$ School of Allied Health Sciences, University for Development Studies, P O Box TL 1883, Tamale, N/R, Ghana

Full list of author information is available at the end of the article
}

delayed neurological development, permanent cognitive impairment, weakened immune systems [2], and a susceptibility to chronic diseases in adulthood [3]. Globally, 178 million children 5 years of age are stunted with the vast majority in South Central Asia and Sub-Saharan Africa [4]. In Ghana, the national prevalence of stunting among children under 5 years was $19 \%$ but there are wide regional variations with $33 \%$ of under five children stunted in the Northern Region according to the recent Demographic and Health Survey [5]. The region with the capital city, Greater Accra, has the least percentage 
of stunted children (10\%). Despite the several interventions being implemented for malnutrition by both Governmental and Non-Governmental Organisations in Northern Region, the rate of decline in stunting is very slow. Stunting decreased from $48.8 \%$ in 2003 to $33.0 \%$ in 2014 in Northern Region but came down from 32 to $14 \%$ within the same period in a neighbouring region $[5,6]$. This slow decline in stunting rate suggests that not all causative factors for malnutrition have been identified and/or are being addressed adequately.

Depression is common among women of reproductive age, and 10 to $15 \%$ of all mothers in developed countries are estimated to suffer from depression [7]. Epidemiological studies and data on the prevalence of depression in Africa are limited but a systematic review involving 35 studies using different depression questionnaires in eight African countries found a depression prevalence of $11.3 \%$ in pregnancy which rose to $18.3 \%$ after birth [8]. In Ghana, two small health centre-based studies reported a depression prevalence of $10.0 \%$ in HIV positive mothers in Eastern Region using Edinburgh Postnatal Depression Scale [9], and mothers of sick children admitted at a tertiary health care facility in Ashanti Region using the Patient Health Questionnaire [10] but in the second study, over $25 \%$ of the mothers had scores corresponding to moderate depression. A recent large study in the Brong Ahafo Region estimated a prevalence of $9.6 \%$ among pregnant women which reduced to $3.8 \%$ after delivery [11]. The combination of women's vulnerability to depression, their responsibility for childcare and the high prevalence of maternal depression in developing countries $[8,12]$ suggests that, maternal mental health could have a substantial influence on the growth of children in these countries.

Evidence suggests that maternal depression adversely affects psychological and intellectual development of children [13-15]. It is plausible for maternal depression to affect a child's physical health and development through interfering with quality of emotional childcare or "mother-child attachment" [16], a known risk factor for poor growth [17], or through negatively affecting mothers' health-promoting behaviours and child-care practices $[18,19]$. Rapid physical growth and development occur in early life when infants and young children depend on the primary caregiver for their social and nutritional needs, and this makes them vulnerable to the effects of their caregivers' mental health problems. While findings from individual studies are conflicting, two systematic reviews $[20,21]$ and a meta-analysis [22] summarising studies on the association between maternal depression and child undernutrition in low and middle income countries have found an association between them.

The aim of this study was to investigate the association between depression among mothers (15-45 years) and stunting in their children (0-59 months) attending Child
Welfare Clinic (CWC) at Bilpiela Health Centre, Tamale, Northern Ghana.

\section{Methods \\ Participants}

An analytical cross-sectional study was performed. The study population consisted of all women (aged 15-45 years) with apparently healthy children under 5 years old seeking CWC services at the Bilpiela Health Centre or its 2 outreach posts in April-May, 2014. Mothers were briefed on the objectives of the study during the weekly CWC sessions and were enrolled to participate in the study conditional to consenting. Among the 392 mothers approached, 384 consented and were interviewed.

Bilpiela is a suburb of Tamale, the capital city of the Northern Region (one of ten administrative regions), and the third largest city by population size. Tamale is located $600 \mathrm{~km}$ north of Accra, the national capital city. Most residents of Tamale are moderate followers of Islam and belong to the Dagbon ethnic group.

\section{Measurements}

Data were collected using a semi-structured questionnaire, the Centre for Epidemiologic Depression Screening (CEDS) Questionnaire and anthropometry. The administration of the questionnaire was undertaken by two final year undergraduate students of the School of Medicine and Health Sciences, UDS, Tamale. The questionnaire was administered in English in a face-to-face interview with the mothers, and for those who did not speak English it was translated and administered in Akan or Dagbani language.

\section{Assessment of socio-demographic characteristics}

Socio-demographic information on the mothers including age, marital status, educational level, religion, and number of previous children were obtained from the respondents. Information was requested on ownership of 14 household items: mobile phone, TV, sewing machine, DVD player, satellite dish, radio, mattress, refrigerator, computer, electric fan, bicycle, motorcycycle/tricycle, animal-drawn cart, and vehicle. These household items are thought to reflect household socio-economic status. Using the 14 household items a wealth score was derived for each household using principal component analysis and the scores were ordered/classified into tertiles. The first tertile represents the lowest socio-economic group; the middle tertile the middle class and the third tertile the highest socio-economic class.

\section{Assessment of stunting}

Anthropometric measurements were done following standard procedures [1] by two undergraduate students during CWC sessions of the Bilpiela Health Centre either at the Centre or at outreach posts. Recumbent 
length was measured for children below the age of 2 years and standing height for the remainder of the children up to the nearest $0.1 \mathrm{~cm}$ using infantometre. Children were weighed naked or wearing minimal clothing being carried by their mothers using the UNISCALE to the nearest $0.1 \mathrm{~kg}$. Birth weight, sex and birthdate were recorded from the child welfare booklet and age was calculated from the date of interview and date of birth. Height-for-age, weight-for-age, and weight-forheight z-scores were derived based on the World Health Organisation (WHO) Multicentre Growth Standard [23], summarised and presented as means and standard deviations and also used to construct categorical variables. A zscore of less than -2 standard deviations was considered as stunting, underweight and wasting for height-for-age, weight-for-age and weight-for-height indices respectively [23]. Stunting was considered as the dependent variable.

\section{Assessment of depression}

Depression status assessment was done using the Centre for Epidemiological Studies Depression (CES-D) Scale [24]. The CES-D scale comprises of 20 questions and responses and is used to assess depressive feelings and behaviours during the past week. Four questions (4, 8, 12, and 16) are statements expressing "positive thoughts" and the responses are scored from 3 to 0 with three indicating that those "thoughts" were rarely had (at most 1 day) and 0 indicating that those "thoughts" were had most days (5-7 days) of the week. The remainder of the questions are statements expressing "negative thoughts" and are reverse scored. The scores are summed up with a possible total score of 60 and a score of $\geq 16$ is indicative of depression. Although not diagnostic, these can be used as proxy measures of depressive disorder after validation against interviews. The CED-S scale scores were added up and a 2-category variable of no depression (score $<16)$ and depression $(\geq 16)$ was generated from the total score so that it was more clinically meaningful than a raw score. Additionally, a 4-category variable of 1. No depression (CES-D score $<16), 2$. Possible depression (16 $\geq$ CES-D score $\leq 19)$, 3 . Depression (20 $\geq$ CES-D score $\leq$ 24 ), and 4. Severe depression (CES-D score $\geq 25$ ) was constructed [25]. Ethical clearance was obtained for the study from the School of Medicine and Health Sciences, University for Development Studies, Tamale, Ghana.

\section{Statistical analysis}

Data analysis was performed using Stata/SE version 11.0 (Stata Corp, College Station, TX, USA). Means and standard deviations were computed for continuous variables and frequencies and percentages for categorical variables. Bivariate analyses were conducted in which maternal depression status (Depressed or Not depressed) was compared with the maternal socio-demographic variables (maternal age, marital status, education level, religion, ethnicity, household wealth tertile) and child characteristics (birthweight, sex, and age) using Chi-square $\left(\chi^{2}\right)$ for proportions and $t$-test for means. Maternal socio-demographic characteristics (age, marital status and household wealth tertile) and child characteristic (birth weight) statistically significant in the bivariate analyses were controlled for in a binary logistic regression model that assessed the association between stunting (dependent variable) and maternal depression (independent variable). In all analyses, the level of statistical significance was set at 0.05 .

\section{Results}

The socio-demographic characteristics by the entire study population and stratified by maternal depression status are presented in Table 1 below. The mean age of the mothers was 27.9 [Standard Deviation (SD) \pm 8.2 ] years and a quarter of the mothers were aged 25-29 years. The majority of the mothers had no education (64.8\%), were married (81.3\%), belonged to Dagomba ethnic group (88.8 \%) and practiced Islamic religion (94.3\%). $20.6 \%$ of the study children were low birth weight. 107 out of the 384 mothers had 20 or more scores on the CES-D screening questionnaire giving a point prevalence of maternal depression of $27.8 \%$ (95\% CI 23.4-32.4\%), and $15.9 \%$ had scores corresponding to possible depression. In exception of maternal age, marital status, household socio-economic wealth status and birth weight, most of the socio-demographic characteristics were evenly distributed among the depressed and non-depressed mothers. Mothers with depression tended to be younger 28.6 $(\mathrm{SD} \pm 8.3)$ years versus $30.6(\mathrm{SD} \pm 8.1)$ years $(p=0.020)$, currently unmarried $26.2 \%$ versus $13.0 \%(p=$ 0.001 ), belong to the poorest household wealth tertile $52.4 \%$ versus $18.5 \%(p<0.001)$ and more likely to have low birth weight babies $32.1 \%$ versus $11.6 \%(p<0.001)$.

Anthropometry information on the children is presented in Table 2. Both the mean anthropometric z-scores for the entire study population and those stratified by age groupings were negative indicating the children in the study were less well-nourished compared to the WHO reference standard population. More children were stunted $16.1 \%$ than underweight $8.9 \%$ and stunting increased with age whilst underweight was relatively stable. As expected the prevalence of wasting was lowest with a rate of $3.4 \%$.

In the unadjusted model (Table 3 ), the children of depressed mothers were 3 times more likely to be stunted compared to children of psychologically sound mothers odds ratio (OR) 3.57 (95 \% Confidence Interval [CI] 1.996.40, $p<0.001)$. Upon adjusting for socio-demographic (maternal age, marital status and household wealth tertile) and child characteristic (birth weight) that were statistically significant in bivariate analyses, the risk of stunting to children of depressed mothers decreased slightly but remain statistically significant $(\mathrm{AOR}=2.48,95 \%$ CI 1.29-4.77, $p=0.0011)$. 
Table 1 Socio-demographic characteristics of the study population, overall and by maternal depression status

\begin{tabular}{|c|c|c|c|c|}
\hline \multirow[t]{2}{*}{ Maternal characteristic } & Total sample $(n=384)$ & No maternal depression $(n=216)$ & Maternal depression $(n=168)$ & \multirow[t]{2}{*}{$P$-value } \\
\hline & Frequency (\%)/Mean ( \pm SD) & Frequency $(\%) /$ Mean $( \pm$ SD) & Frequency (\%)/Mean $( \pm$ SD) & \\
\hline Mean age, years & $27.9( \pm 8.2)$ & $30.6( \pm 8.1)$ & $28.6( \pm 8.3)$ & 0.020 \\
\hline Age group, years & & & & 0.307 \\
\hline$<20$ & $35(9.1)$ & $15(6.9)$ & $20(11.9)$ & \\
\hline $20-24$ & $82(21.4)$ & $42(19.4)$ & $40(23.8)$ & \\
\hline $25-29$ & $76(19.8)$ & $41(19.0)$ & $35(20.8)$ & \\
\hline $30-34$ & $64(16.7)$ & $40(18.5)$ & $24(14.3)$ & \\
\hline $35-39$ & $53(13.8)$ & $32(14.8)$ & $21(12.5)$ & \\
\hline $40+$ & $74(19.3)$ & $46(21.3)$ & $28(16.7)$ & \\
\hline Education & & & & 0.819 \\
\hline No education & $249(64.8)$ & $139(64.4)$ & $110(65.5)$ & \\
\hline Some education & $135(35.2)$ & 77 (35.6) & $58(34.5)$ & \\
\hline Marital status & & & & 0.001 \\
\hline Married & $312(81.3)$ & $188(87.0)$ & $124(73.8)$ & \\
\hline Currently unmarried & $72(18.8)$ & $28(13.0)$ & $44(26.2)$ & \\
\hline Ethnicity & & & & 0.698 \\
\hline Dagomba & $341(88.8)$ & $193(89.4)$ & $148(88.1)$ & \\
\hline Other tribes & $43(11.2)$ & $23(10.6)$ & $20(11.9)$ & \\
\hline Religion & & & & 0.868 \\
\hline Islam & $362(94.3)$ & $204(94.4)$ & $158(94.0)$ & \\
\hline Other religions & $22(5.7)$ & $12(5.6)$ & $10(6.0)$ & \\
\hline Household wealth tertile & & & & $<0.001$ \\
\hline Poorest & $128(33.3)$ & $40(18.5)$ & $88(52.4)$ & \\
\hline Medium & $128(33.3)$ & $67(31.0)$ & $61(36.3)$ & \\
\hline Richest & $128(33.3)$ & $109(50.5)$ & $19(11.3)$ & \\
\hline \multicolumn{5}{|l|}{ Child characteristic } \\
\hline Mean age, months & $19.5( \pm 16.1)$ & $18.7( \pm 15.7)$ & $20.7( \pm 16.5)$ & 0.215 \\
\hline Age, months & & & & 0.070 \\
\hline $0-5$ & $84(21.9)$ & $56(25.9)$ & $28(16.7)$ & \\
\hline $6-23$ & $173(45.1)$ & $89(41.2)$ & $84(50.0)$ & \\
\hline $24-59$ & $127(33.1)$ & $71(32.9)$ & $56(33.3)$ & \\
\hline Sex & & & & 0.728 \\
\hline Female & $189(49.2)$ & $108(50.0)$ & $81(48.2)$ & \\
\hline Male & $195(50.8)$ & $108(50.0)$ & $87(51.8)$ & \\
\hline Mean Birth weight, kg & $2.7( \pm 0.40)$ & $2.9( \pm 0.40)$ & $2.6( \pm 0.30)$ & $<0.001$ \\
\hline Birth weight, kg & & & & $<0.001$ \\
\hline$<2.5$ & 79 (20.6) & $25(11.6)$ & $54(32.1)$ & \\
\hline$\geq 2.5$ & $305(79.4)$ & $191(88.4)$ & $114(67.9)$ & \\
\hline
\end{tabular}

\section{Discussion}

\section{Main findings}

16.1 and $27.8 \%$ of our study population have child stunting and maternal depression respectively and we found an increased risk of stunting in children of depressed mothers when compared to children of non-depressed mothers (AOR 2.48, CI 1.29-4.77) even after adjusting for potential confounders in a multivariate analysis. To our knowledge this is the first study to evaluate the impact of maternal depression on the nutritional status of Ghanaian children. 
Table 2 Anthropometric status of children

\begin{tabular}{lllll}
\hline Age (months) & $0-5(N=84)$ & $6-23(N=173)$ & $24-59(N=127)$ & $0-59(N=384)$ \\
\hline Z-score (Mean \pm SD) & & & & $-0.82 \pm 1.10$ \\
$\quad$ Height-for-age & $-0.43 \pm 0.96$ & $-0.86 \pm 1.11$ & $-0.71 \pm 0.89$ & $-0.73 \pm 0.92$ \\
$\quad$ Weight-for-age & $-0.57 \pm 0.96$ & $-0.82 \pm 0.91$ & $-0.37 \pm 0.73$ & $-0.41 \pm 0.75$ \\
$\quad$ Weight-for-height & $-0.33 \pm 0.66$ & $-0.48 \pm 0.80$ & & 1.09 \\
Prevalence (\%, 95\% Cl) & & & $22.8(15.4-30.2)$ & $16.1(12.4-19.8)$ \\
$\quad$ Stunting & $6.0(0.8-11.1)$ & $16.2(10.6-21.7)$ & $9.4(4.3-14.6)$ & $8.9(6.0-11.7)$ \\
Underweight & $7.1(1.5-12.8)$ & $9.2(4.9-13.6)$ & $2.4(-0.3-5.0)$ & $3.4(1.6-5.2)$ \\
$\quad$ Wasting & $2.4(-0.9-5.7)$ & $4.6(1.5-7.8)$ & &
\end{tabular}

The percentages of child growth indicators measured in our study were lower compared to the regional averages of 33, 6.3 and $20 \%$ for stunting, wasting and underweight [6], but we also found that stunting increased dramatically as the children aged suggesting problems with complementary feeding and accumulation of repeated exposures to infections. In Ghana, $22 \%$ of children in the rural areas are stunted compared to $15 \%$ in urban areas and rural children are more likely to experience nutritional problems compared to urban children [6]. The semi-urban nature of our study area which is in the Tamale Metropolis may explain the lower undernutrition rates measured.

There are notable disparities in socio-demographic, socio-economic and child characteristic between mothers with and without depression. Our study showed that mothers with depression were younger; currently unmarried, and were more likely to belong to the poorest household wealth tertile, or to have low birth weight babies. Data are unavailable on the determinants of maternal depression in Ghana for comparison. In Nigeria, Adewuya et al found that not currently being married increased the

Table 3 Odds ratios for stunting in children of mothers with depression compared to children of mothers without depression

\begin{tabular}{|c|c|c|c|}
\hline Variable & $\begin{array}{l}\text { Model } 1 \text { (Unadjusted) } \\
\text { OR (95 \% Cl) }\end{array}$ & $\begin{array}{l}\text { Model } 2 \text { (Adjusted for child characteristic) } \\
\text { OR (95\% Cl) }\end{array}$ & $\begin{array}{l}\text { Model } 3 \text { (Adjusted for child and maternal } \\
\text { characteristics) OR ( } 95 \% \text { Cl) }\end{array}$ \\
\hline \multicolumn{4}{|l|}{ Maternal depression } \\
\hline No & 1.00 & 1.00 & 1.00 \\
\hline Yes & $3.57^{*}(1.99-6.40)$ & $3.49 *(1.91-6.35)$ & $2.48^{*}(1.29-4.77)$ \\
\hline \multicolumn{4}{|l|}{ Birth weight (kg) } \\
\hline$\geq 2.5$ & & 1.00 & 1.00 \\
\hline$<2.5$ & & $1.12(0.58-2.15)$ & $1.04(0.53-2.04)$ \\
\hline \multicolumn{4}{|l|}{ Maternal Age (years) } \\
\hline $15-19$ & & & 1.00 \\
\hline $20-24$ & & & $1.47(0.45-4.79)$ \\
\hline $25-29$ & & & $1.90(0.57-6.31)$ \\
\hline $30-34$ & & & $1.16(0.32-4.25)$ \\
\hline $35-39$ & & & $1.80(0.48-6.65)$ \\
\hline $40-45$ & & & $1.22(0.36-4.10)$ \\
\hline \multicolumn{4}{|l|}{ Marital status } \\
\hline Married & & & 1.00 \\
\hline Not currently married & & & $0.78(0.36-1.71)$ \\
\hline \multicolumn{4}{|l|}{ Household wealth tertile } \\
\hline Richest & & & 1.00 \\
\hline Medium & & & $2.67(1.09-6.59)$ \\
\hline Poorest & & & $3.40(1.36-8.48)$ \\
\hline
\end{tabular}

Model 2 was adjusted for child's birth weight

Model 3 was adjusted for child's birth weight, maternal age, marital status and household wealth tertile

Not currently married category includes unmarried, divorced and widowed mothers

${ }^{*} p<0.001$ 
risk of depression in pregnant women [26]. A systematic review on low and lower middle income countries identified young age, and being unmarried as risk factors and more education as a protective factor for common perinatal mental disorders [27].

We however estimated a higher rate of depression among mothers than previously reported elsewhere in the country; $3.8-11.3 \%[9-11,28]$. All the previous studies were conducted outside Northern Ghana, two involved mothers with special circumstances i.e., HIV positive mothers and mothers of sick and hospitalized children, and the other two were on women in a vitamin A trial. Three different depression screening tools and cut-offs were used in the previous studies. Clearly there is some degree of variation among the estimated prevalence rates but differences in the population studied, study design, depression screening tool and cut-off make these incomparable and these same factors may also explain some of the variation. Our rate is however closer to a prevalence rate of depression (26.6\%), measured among pregnant women at a tertiary hospital in the Ashanti Region, Ghana [29]. The high prevalence of depression measured in our study can be partly explained by the lack of formal education among the mothers; $64.8 \%$ of mothers in our study had no form of education. Despite several health interventions, the prevalence of undernutrition in the Northern Region, Ghana has not reduced as expected. Evidence from South East Asia suggests that despite appreciable levels of food security and economic growth, child malnutrition problems are prevalent, a phenomenon referred to as the Asian "enigma" and attributed to low social status of women and/or a lack of women's control over resources [30]. Inadequate care for children is one of the underlying causes of malnutrition, along with food insecurity and poor access to health services and unhealthy environment [31]. In this study we explored the association between maternal depression and child stunting in order to inform nutrition programming.

Our study findings agree with some studies but not others and the population studied, study design, and depression screening tools are likely to influence these associations. In Indian and Pakistan an association was detected for prenatal depression and poor child growth [32-34], but another study on British Pakistanis living in Britain did not find an association [35]. A synthesis of several of these studies concluded that there is an association between maternal depression and poor child growth and development and that this association seems to operate in low socio-economic societies only [20-22].

Maternal depression possibly promotes unhealthy lifestyles, poor health-seeking behaviours, deficient physical and emotional care and psychosocial stimulation of the infant; and these coupled with low household socioeconomic status impair child growth and development
[18]. Depression is known to reduce maternal interest in child rearing and caring activities [16]. In one study infants of depressed mothers were less likely to be fully immunized at 12 months compared with infants of psychological well mothers reflecting a lack of appropriate health-seeking behaviour in depressed mothers [33]. In Ghana, postnatal depression symptoms in HIV positive mothers were associated with increased diarrhoeal episodes in children [9] and in Nigeria children of depressed mothers were more likely to have poor growth, to discontinue breastfeeding, and to have more persistent diarrhoea [36].

\section{Strengths and limitations of study}

The use of a cross-sectional study design in which both maternal depression and child stunting were assessed simultaneously does not allow for causal inference and ascertainment of the temporal order of exposure and outcome. We measured the association between maternal depression and child stunting and assumed mothers with depression are more likely to have stunted children but it could well have been poor growth in children led to depression in their mothers. We have used a validated and widely used screening questionnaire, CES-D questionnaire, in assessment of maternal depression. CES-D has not been validated in Ghana and therefore, no clinical threshold (i.e., cut-off score) has been established to distinguish between those depressed and not depressed and its reliability in this context is unknown. In addition, our study did not include a clinical diagnostic interview or ethnographic assessment that could be used as a reference standard. Some of the women we have classified as depressed may not actually have depression as CES-D questionnaire is a screening tool and not diagnostic. We failed to control for childcare support which has been found to moderate the effect of maternal psychopathology in community-based studies in low and middle income countries, such as Nigeria [26].

\section{Conclusions}

There is a moderate level of stunting in children but the mothers of these children have a high level of depression in Northern Ghana, and these two health conditions are associated. Further research is needed to identify the determinants of maternal depression, and to verify the link between maternal depression and child stunting.

\section{Additional files}

Additional file 1: Study dataset. (DTA $53 \mathrm{~kb}$ )

Additional file 2: Study questionnaire. (PDF $390 \mathrm{~kb}$ )

\section{Acknowledgements}

We are very grateful to management of the Bilpiela Health Centre for allowing us to use their health facility for this study and to the mothers who sacrificed their time to respond to the questionnaire. We thank Anna Lagoh and Stella Manu for collecting the data. 


\section{Funding}

Not applicable.

\section{Availability of data and materials}

The data analysed for the paper and the questionnaire used for data collection have been provided as Additional files 1 and 2 .

\section{Authors' contributions}

AW conceptualized the study, supervised data collection and drafted the paper. KAM analysed the data and contributed to writing of paper. Both authors read and approved the final manuscript.

\section{Authors' information}

AW: PhD; Lecturer at School of Allied Health Sciences, University for Development Studies, Tamale, Ghana.

KAM: PhD; Lecturer at School of Public Health, KNUST, Kumasi, Ghana.

\section{Competing interests}

The authors declare that they have no competing interests.

\section{Consent for publication}

Not applicable.

\section{Ethics approval and consent to participate}

Ethical clearance for the study was obtained from the School of Medicine and Health Sciences, University for Development Studies, Tamale, Ghana. Informed consent was obtained from each mother before she was enrolled into the study.

\section{Author details}

${ }^{1}$ School of Allied Health Sciences, University for Development Studies, P O Box TL 1883, Tamale, N/R, Ghana. ${ }^{2}$ School of Public Health, KNUST, Kumasi, Ghana.

\section{Received: 21 November 2015 Accepted: 19 August 2016}

\section{Published online: 24 August 2016}

\section{References}

1. World Health Organisation. Physical status: the use and interpretation of anthropometry, WHO technical report series. Geneva: WHO; 1995.

2. Victora CG, Adair L, Fall C, Hallal PC, Martorell R, Richter L, Sachdev HS, Maternal and Child Undernutrition Study Group. Maternal and child undernutrition: consequences for adult health and human capital. Lancet. 2008:371(9609):340-57.

3. Barker DJ. The developmental origins of chronic adult disease. Acta Paediatr. 2004;93:26-33.

4. Bhutta ZA, Ahmed T, Black RE, Cousens S, Dewey K, Giugliani E, Haider BA Kirkwood B, Morris SS, Sachdev HPS. What works?: Interventions for maternal and child undernutrition and survival. Lancet. 2008:371(9610):417-40.

5. GSS, GHS, and ICF. Ghana demographic and health survey 2014. Rockville: GSS, GHS, and ICF International; 2014

6. GSS, NMIMR, and ORC. Ghana demographic and health survey, 2003. Accra: Ghana Statistical Service; 2004.

7. O'hara MW, Swain AM. Rates and risk of postpartum depression-a meta-analysis. Int Rev Psychiatry. 1996;8(1):37-54.

8. Sawyer A, Ayers S, Smith H. Pre- and postnatal psychological wellbeing in Africa: a systematic review. J Affect Disord. 2010;123:17-29.

9. Okronipa HET, Marquis GS, Lartey A, Brakohiapa L, Perez-Escamilla R, Mazur RE Postnatal depression symptoms are associated with increased diarrhoea among infants of HIV-positive Ghanaian mothers. AIDS Behav. 2012:16:2216-25.

10. Gold KJ, Spangenberg K, Wobil P, Schwenk TL. Depression and risk factors for depression among mothers of sick infants in Kumasi, Ghana. Int J Gynecol Obstet. 2013;120(3):228-31.

11. Weobong B, ten Asbroek AH, Soremekun S, Danso S, Owusu-Agyei S, Prince M, Kirkwood BR. Determinants of postnatal depression in rural Ghana: findings from the Don population based cohort study. Depress Anxiety. 2015;32(2):108-19.

12. Gavin NI, Gaynes BN, Lohr KN, Meltzer-Brody S, Gartlehner G, Swinson T. Perinatal Depression: A Systematic Review of Prevalence and Incidence. Obstet Gynecol. 2005;106(5, Part 1):1071-83.

13. Cummings EM, Davies PT. Maternal depression and child development. J Child Psychol Psychiatry. 1994:35(1):73-122.

14. Cooper PJ, Murray L. Postnatal depression. BMJ. 1998;316(7148):1884-6.
15. Rondó PHC, Rezende G, Lemos JO, Pereira JA. Maternal stress and distress and child nutritional status. Eur J Clin Nutr. 2013:67(4):348-52.

16. Cooper PJ, Tomlinson M, Swartz L, Woolgar M, Murray L, Molteno C. Postpartum depression and the mother-infant relationship in a South African peri-urban settlement. Br J Psychiatry. 1999;175(6):554-8.

17. Widdowson EM. Mental contentment and physical growth. Lancet. 1951; 257(6668):1316-8

18. Rahman A, Harrington R, Bunn J. Can maternal depression increase infant risk of illness and growth impairment in developing countries? Child: care. Health Dev. 2002;28(1):51-6.

19. Casey P, Goolsby S, Berkowitz C, Frank D, Cook J, Cutts D, Black MM, Zaldivar N, Levenson S, Heeren T, Meyers A. Maternal depression, changing public assistance, food security, and child health status. Pediatrics. 2004;113(2):298-304.

20. Hurley K, Surkan P, Black M. Maternal Depression and Child Growth in Developing Countries: A Focus on the Postnatal Period. In: Preedy VR, editor. Handbook of Growth and Growth Monitoring in Health and Disease. New York: Spinger; 2012. p. 2023-46.

21. Stewart RC. Maternal depression and infant growth-a review of recent evidence. Matern Child Nutr. 2007;3(2):94-107.

22. Surkan PJ, Kennedy CE, Hurley KM, Black MM. Maternal depression and early childhood growth in developing countries: systematic review and metaanalysis. Bull World Health Organ. 2011:89:607-15.

23. World Health Organisation. WHO Child Growth Standards based on length/ height, weight and age. Acta Paediatr. 2006;450:76-85.

24. Radloff LS. The CES-D scale a self-report depression scale for research in the general population. Appl Psychol Meas. 1977;1(3):385-401.

25. Zhang MY. Handbook of rating scales in psychiatry. Changsha: Hunan Science and Technology Press; 1998.

26. Adewuya AO, Ola BA, Aloba OO, Dada AO, Fasoto OO. Prevalence and correlates of depression in late pregnancy among Nigerian women. Depress Anxiety. 2007:24(1):15-21.

27. Fisher J, Mello MC, Patel V, Rahman A, Tran T, Holton S, Holmes W. Prevalence and determinants of common perinatal mental disorders in women in low-and lower-middle-income countries: a systematic review. Bull World Health Organ. 2012;90(2):139-49.

28. Weobong B, Akpalu B, Doku V, Owusu-Agyei S, Hurt L, Kirkwood B, Prince $M$. The comparative validity of screening scales for postnatal common mental disorder in Kintampo, Ghana. J Affect Disord. 2009;113(1):109-17.

29. Bindt C, Appiah-Poku J, Te Bonle M, Schoppen S, Feldt T, Barkmann C, Koffi M, Baum J, Nguah SB, Tagbor H, Guo N. Antepartum depression and anxiety associated with disability in African women: cross-sectional results from the CDS Study in Ghana and Côte d'Ivoire. PloS one. 2012;7(10):e48396.

30. Ramalingaswami $V$, Jonsson U. Commentary: the Asian enigma. The Progress of Nations 1966. Nutrition, UNICEF. New York: United Nations Children's Fund; 1996

31. Unicef. Strategy for improved nutrition of children and women in developing countries. New York: Unicef; 1990

32. Patel V, DeSouza N, Rodrigues M. Postnatal depression and infant growth and development in low income countries: a cohort study from Goa, India. Arch Dis Child. 2003:88(1):34-7.

33. Rahman A, lqbal Z, Bunn J, Lovel H, Harrington $\mathrm{H}$. Impact of maternal depression on infant nutritional status and illness: a cohort study. Arch Gen Psychiatry. 2004;61(9):946-52

34. Anoop S, Saravanan B, Joseph A, Cherian A, Jacob KS. Maternal depression and low maternal intelligence as risk factors for malnutrition in children: a community based case-control study from South India. Arch Dis Child. 2004;89(4):325-9.

35. Husain N, Cruickshank JK, Tomenson B, Khan S, Rahman A. Maternal depression and infant growth and development in British Pakistani women: a cohort study. BMJ Open. 2012:2(2):e000523.

36. Adewuya AO, Ola BO, Aloba OO, Mapayi BM, Okeniyi JAO. Impact of postnatal depression on infants' growth in Nigeria. J Affect Disord. 2008;108(1-2):191-3. 